\title{
HERNIA AND PR'OLAPSE OF THE VITREOUS AND PROLAPSE OF THE IRIS IN CONNECTION WITH THE CATARACT OPERATION
}

\author{
BY \\ Mauno Vannas \\ THE OPHTHALMIC CLINIC OF THE UNIVERSITY OF \\ HELSINKI, FINLAND
}

At the operation for cataract the iris is usually replaced with the spatula and the wound closed definitely. Although this is, as a rule, so simple, we know that there are very often cases where difficulties arise in the reposition of the iris. This question will be. discussed here on the basis of some of my earlier studies later extended.

From Dejean's and especially Ida Mann's investigations we know that when the human embryo is $1 \mathrm{~cm}$. in length, the arteria hyaloidea and the veins surrounding it pass conically from behind to the front, to the posterior surface of the lens. These veins, together with the fibres between them, form the primary vitreous. Around it the retina soon grows the secondary vitreous. To illustrate the conditions at the time of birth I have compared the primary vitreous with the old-fashioned stethoscope, the smaller end being on the papilla, the tube passing horizontally from behind forward, and the larger end being on the posterior surface of the lens. What is inside the stethoscope belongs to the primary vitreous, and what is around it to the avascular, more solid secondary. vitreous. The walls of the stethoscope then form the intervening membrane between these two parts of the vitreous.

During the first four years the tube of the stethoscope as it were sinks deeper and becomes obliterated. Thus there arises a practically vertical posterior wall to the primary vitreous separating it from the secondary vitreous behind.

Whoever examines the front parts of the vitreous in the optic section of the slit-lamp will observe that immediately behind the lens an optically empty narrow space begins. Koeppe called it the post-lenticular and Vogt the retro-lental space. According to the latter, it contains aqueous humour.

Inspired by an observation made by Comberg I have, as I think, proved that such a post-lenticular or retro-lental space does not exist. Omitting explanations, when I removed the cornea and the lens from an enucleated human eye or that of certain animals and then studied the front parts of the vitreous, now exposed to the open air, with the aid of a slit-lamp, this so-called retro-lental space

\footnotetext{
* Received for publication, April 22, 1948.
} 
was as visible as in an untouched eye, and when I examined eyes after intracapsular lens extraction the space of Koeppe and Vogt was also seen in all of them. Thus the space behind the lens that appears empty really belongs to the vitreous. It is the residual part of the primary vitreous and therefore I have suggested for it the name "primary space."

The membrane where the vitreous was believed to begin is in point of fact within the vitreous. It is the border between the primary and the secondary vitreous and consequently may be called intervening membrane. The practical importance of these questions will be reverted to later, but first, what happens to the front surface of the vitreous during and after the extraction of the lens from the eye?

If we remove totally the cornea and the lens from the eye of a human or a pig we see that the smooth surface of the vitreous is really covered by a very thin membrane which can be grasped with capsule forceps and, to some extent, folded, even if it is more fragile than the lens capsule. If a cut is made on the front surface of the vitreous its edges form lighter folds and, if the eye is then slightly pressed, the vitreous begins to emerge from the wound. To bring out more vitreous the pressure should be slightly increased probably due to the fact that the thinner primary vitreous escapes first, and when the intervening membrane is broken, the more solid secondary vitreous. However, it is not always possible to notice such a difference.

It is known that the front surface of the vitreous after the cataract operation tends to be pushed into the anterior chamber. But the size and form of the distention varies greatly, especially according to whether the extraction has been extra- or intracapsular. Particularly after intracapsular extraction of the lens the front surface

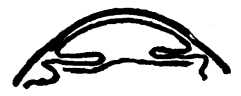

FIG. 1.

About $\frac{1}{4}$ of the cases (no hernia at all).

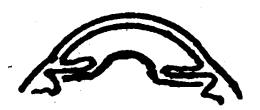

Figs. 2 and 3.

The commonest types.

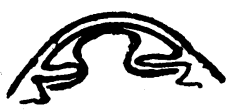

FIG. 4.

About 10 per cent. of the cases.

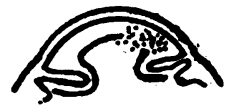

FIG $_{\text {IG. }}$.

Front membrane partially perforated.

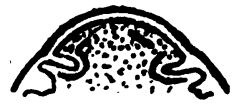

FIG. 6.

Front membrane largely ruptured. The vitreous fills the whole anterior chamber and makes it deep. 
of the vitreous tends to be pushed into the anterior chamber in the shape of the head of a fungus, forming a kind of hernia. There were two kinds of hernias. I have called the one with an intact surface membrane simple, and the others complicated (Figs. 1-6).

No hernia has occurred after intracapsular cataract extraction in about $\frac{1}{4}$ of recent cases. In nearly 10 per cent., on the other hand, the hernia is so high that it reaches the posterior surface of the cornea! The lower hernias are between these limits. If iridectomy has been performed the hernia is, as a rule, slightly higher.

The complicated largest hernias have, of course, no surface membrane and the vitreous flows into the anterior chamber which is then generally exceptionally deep.

Proceeding to study the prolapse of the iris and the vitreous, it seems advisable to deal first with the so-called semi-prolapse or the danger of prolapse, i.e., the pupil drawn up towards the incision. Among such cases the cause of this updrawal of the pupil is surprisingly often the fact that there are some residual fine fibres of the embryonic pupillary membrane and these fibres-overlooked at the routine examination-stretch and wedge themselves into the wound at the extraction. Other causes are the torsion of the broken, or even unbroken, front membrane of the vitreous around the pupillary margin, and the wedging of this membrane into the wound. Such cases, I believe, occur more frequently after tumbling extractions. Drawing up of the pupil may be due also to other causes.

Though prolapse of the iris and of the vitreous are not inseparable Siamese twins, they are so closely connected that we can say : where the one is, there the other is on the way-corpus ante portas !

Here the general precautionary measures which have been invaluable to cataract patients will be omitted; a previously laid. corneo-scleral suture must probably now be included among them. At our clinic the incision is closed after extracting the lens with a triangle suture $\left(\operatorname{Vannas}^{2}\right)$, but the threads are not yet tied. Instillation of eserine which de Wecker introduced as long ago as 1886 is a very valuable aid which has an immediate effect. The use of eserine to straighten the columns of the iris is indicated also in cases where iridectomy has been performed.

In any extensive series of operations, we can distinguish the following different groups : 1. Miosis occurs already after the first instillation of eserine. 2. The pupil does not contract even after many instillations, although the pupil moved normally before the operation. What is the cause of this difference?

The explanation is probably to be seen in Figs. 1-6. There is a hernia of the vitreous in the anterior chamber.

If the hernia is simple and shallow the pupillary margin easily 
glides along the surface of the vitreous and the result is miosis. With a hernia of medium height the result is + or - . In high hernias the stem of the fungus can narrow but the head remains in the anterior chamber. The cases in which the front membrane is only slightly broken are an intermediate form. In severe and complicated hernias, again (Fig. 6) miosis may be prevented by the vitreous filling the anterior chamber, especially if. some of the more solid secondary vitreous has entered the chamber. Even with the strongest miotics it is then impossible to contract the pupil. This is also understandable, as by contracting, the iris prevents the vitreous from escaping from the anterior chamber, except possibly in cases where the vitreous is fluid.

Next-the actual prolapse and loss of the vitreous. In these cases the front membrane of the vitreous always ruptures. Under these circumstances it seems surprising that the loss of vitreous often remains comparatively small; sometimes it seems as if the slight flow would cease spontaneously. This may possibly be explained by the observations described above: the more liquid primary vitreous escapes first and then-if the intervening membrane ruptures-the secondary, vitreous. An exception is the case in which the vitreous is more liquid and the difference in fluidity between the primary and secondary vitreous has disappeared. It is possible that the intervening membrane is then also weaker.

It is well known that whenever there is loss of vitreous, the risk of a persistent prolapse of the iris is great. The most severe case is an inversion of the iris (retroflexio iridis).

Now a few words as to the practical side of the question, the replacement of the prolapsed iris. I have already spoken of the important part of eserine in this reposition. For this purpose.we have at our disposal the ordinary smooth iris spatula. Comberg has proposed a repositor with a ball end and a point on it. This, however, is so large that the wound must be opened too much and I, for my part, have not been able to use it satisfactorily. L. Müller already recommended the use of small forceps for the replacement of the iris prolapse and especially for retroversion of the iris. But this necessitates a rather wide opening of the wound. The most important requirement of a good repositor is that it can be used so that the cataract wound remains closed as much as possible.

The old smooth iris spatula satisfies this demand. But in severe cases it has the drawback that it cannot grip the iris but slips on its surface. Therefore we have made some of our spatulas with a small sharp needle-point. We place it into the eye perpendicularly and then it is easy to get hold of the iris.

An ordinary injection needle with a point suitably bent serves 
the same purpose. The great advantage of this needle is that the wound need be opened minimally. A sharp cystitome can also be used. Both these instruments have the advantage that it is possible even in severe cases to grasp the posterior surface of the iris.

But how shall we manage the cases where the iris will repeatedly fall back into the wound after we already have succeeded in replacing it. Here, and generally in severe cases, I have observed that it helps to stretch and slightly press the iris. After getting a firm hold of the iris it should not be released but kept stretched towards the centre of the anterior chamber, then a slight and cautious pressure on the posterior surface of the cornea is applied, the nearer the periphery the better.

Considering the effect of such a centripetal stretching and postero-anterior pressure in the light of Figs. 5 and 6 it is apparent that it is an effective means of emptying the vitreous from the angle of the anterior chamber, which can be achieved by no miotics. And on the other hand, when this angle is emptied and the vitreous in the anterior chamber has diminished, the action of the eserine is stronger. Injury to the endothelium should, of course, be avoided.

Now the question arises whether there is a risk of rupturing the front membrane of the vitreous with the sharp point of the repositor? There is, but in all cases with real loss of vitreous, the front membrane is already ruptured; also, I have noticed that, where the cataract has been extracted intracapsularly after tumbling the lens, the front membrane was ruptured 8-10 days after the operation in about 8 per cent. of the cases, although the extraction was made without loss of vitreous.

When the delivery of the lens has been made directly without tumbling, this figure seems to be somewhat lower. It is thus possible that the membrane can be ruptured already with a simple careful reposition of the iris using the ordinary smooth spatula, or even as a result of extraction only. The replacement and avoiding of a prolapse is in any case more important than preserving the front membrane intact.

In cases where, in spite of our efforts, reposition does not succeed iridectomy is, of course, indicated. It should then extend as far as the root of the iris. After iridectomy a careful replacement of the iris is by no means less important than after extraction through a round pupil.

All that has been stated above concerns mainly the prolapse at extraction of the cataract. I do not intend to deal with the postoperative prolapse, but I should like to say that it is a complication the correction of which, I think, is more difficult than the cataract operation itself. Here it is most important that the patient is calm 
and the eye as soft and insensible as possible (preferably cocaine). After that it is also important to insert the needle of the injection syringe perfectly painlessly into a conjunctival fold elevated by forceps. From this point work gradually to the deeper parts. An incautious handling of the needle can wholly spoil our work almost before we have started.

\section{Summary}

In animal tests and experiments on enucleated human eyes the writer has studied the front membrane of the vitreous. In many cases some vitreous comes out fairly easily and this prolapse seems to stop almost of its own accord, starting again only if the pressure on the bulb is further increased. A similar two-stage prolapse is rather often observed after the cataract operation, and it can be assumed that this is due to the fact that the primary vitreous (the space called post-lenticular by Koeppe and retro-lental by Vogt) extrudes first and that the more solid secondary vitreous prolapses only after the intervening membrane has ruptured.

On the basis of the writer's observations it depends essentially on the state of the front parts of the vitreous whether the size of the pupil can be reduced and the danger of prolapse of the iris and vitreous be avoided after cataract extraction. Especially after intracapsular extraction the vitreous tends to push into the anterior chamber as a fungus-like hernia. In simple hernias (front membrane of vitreous intact) the anterior chamber is usually of ordinary depth and the lower the hernia is, the more easily does the pupil contract with eserine. In complicated hernias of the vitreous (front membrane ruptured) the hernia is usually larger, the anterior chamber deeper, and the greater the quantity of vitreous that escapes into the anterior chamber, the less is the contracting effect of eserine on the pupil. In extreme cases the pupil which contracts after dropping in the eserine forms a " neck" which may even prevent the vitreous from escaping backwards from the anterior chamber. On this account we cannot in such cases reduce the size of the pupil ever' with the strongest miotics, at least not if some of the more solid secondary vitreous has also entered the anterior chamber.

In cases where replacement is difficult a good repositor of the iris should satisfy two requirements : first, such reposition should be possible that the cataract wound need only be slightly opened and, secondly, the instrument should have a sharp point in order to grasp the front surface of the iris; if necessary, it must be possible to grasp also the posterior surface when reposition with an ordinary smooth spatula cannot be done. An injection needle 
with a bent point, a spatula equipped with a sharp point, and a small-size cystitome are recommended as repositors. In difficult cases one may try to express from between the iris and the cornea the vitreous that has extruded into the anterior chamber.

\section{REFERENCES}

MANN.-Jl. of Anat., Vol. LXIl, p. 290, 1928 ; Cit. by Centralbl.f.g. Ophthal., Vol. XX, p. 326, 1929.

Trans. Ophthal. Soc. U.K., Vol. XLVII, p. 172, 1927.

DEJEAN.-Arch. d'Anat., d'Hist. et Embryol., Vol VI, p. 65, 1926 ; Cit. by Centralbl.f. g. Ophthal., Yol. XVIII, p. 120, 1927.

— Arch.d'Ophtal., Vol. XLVI, p. 477, 1929; Arch. d'Ophtal., Vol. XLVII, p. $459,1930$.

KOEPPE.-Arch. d'Ophtal., Vol. XCVI, p. 232, 1918.

VoGT.-Klin. Monatsbl. f. Augenheilk., Vol. LI, p. 129,1913 and Atlas der Spaltlampeńmikroskopie, 1921.

Coмвerg.-Klin. Monatsbl.f. Augenheilk., Vol. LXXXVIII, p. 104, 1932.

_ Klin. Monatsbl. f. Augenheilk., Vol. CII, p. 44, 1939.

WECKER.-Ann. d'Ocul. Vol. XCV, p. $125,1886$.

Müller, L-Klin. Monatsbl. f. Augenheilk., Vol. XL, pp. 358 and 505, 1902.

VANNAS.-Klin. Monatsbl. f. Augenheilk., Vol. LXXXIX, p. 318, 1932.

- Nordisk Medicin, Vol. XXX, p. 1055, 1946.

\section{ANNOTATIONS}

\section{Case Histories}

The history of a case forms an essential part of any medical or surgical consultation. It depends largely on the type of patient you are dealing with whether the history is long drawn out or condensed. Some lady patients, of the type of Mrs. Nickleby, are exceedingly diffuse and far from clear headed. Not often does one meet such a laconic specimen as that recounted ip Sir James Paget's Life. "What's that?" said a Yorkshireman, thrusting out his lower lip for inspection. "That's cancer" said Paget. "What's to be done with it ?" "Cut it out." "What's your fee?" "Two guineas." We have all suffered in our time from the voluble lady who brings with her a reticule or attache case full of spectacles and prescriptions and means to have her money's' worth in conversation if in nothing else.

As a general rule it is a wise plan to let the patient have her say without interruption. Occasionally it may be needful to ask a leading question, but these are best avoided if possible. A glaucoma case, that rushes in late for his appointment and says that his eye went funny a few days ago and that he wishes to be reassured as to its condition, should certainly be asked how his eye went funny; for he will probably present you with the diagnosis by saying 